\title{
Effects of Age and Sex on Estimated Diabetes Prevalence Using Different Diagnostic Criteria: The Tromsø OGTT Study
}

\author{
Moira Strand Hutchinson, ${ }^{1,2}$ Ragnar Martin Joakimsen, ${ }^{1,2}$ Inger Njølstad, ${ }^{3}$ \\ Henrik Schirmer, ${ }^{2}$ Yngve Figenschau, ${ }^{1,2,4,5}$ Johan Svartberg, ${ }^{1,2}$ and Rolf Jorde ${ }^{1,2}$ \\ ${ }^{1}$ Tromsø Endocrine Research Group, Department of Clinical Medicine, University of Tromsø, 9037 Tromsø, Norway \\ ${ }^{2}$ Division of Internal Medicine, University Hospital of North Norway, 9038 Troms $\varnothing$, Norway \\ ${ }^{3}$ Department of Community Medicine, University of Tromsø, 9037 Tromsø, Norway \\ ${ }^{4}$ Department of Medical Biology, University of Tromsø, 9037 Tromsø, Norway \\ ${ }^{5}$ Division of Laboratory Medicine, University Hospital of North Norway, 9038 Tromsø, Norway
}

Correspondence should be addressed to Moira Strand Hutchinson; moira-ylva.hutchinson@uit.no

Received 27 September 2012; Revised 4 December 2012; Accepted 5 December 2012

Academic Editor: Mario Maggi

Copyright (c) 2013 Moira Strand Hutchinson et al. This is an open access article distributed under the Creative Commons Attribution License, which permits unrestricted use, distribution, and reproduction in any medium, provided the original work is properly cited.

$\mathrm{HbA}_{1 \mathrm{c}} 6.5 \%$ has recently been recommended as an alternative diagnostic criterion for diabetes. The aims of the study were to evaluate the effects of age, sex, and other factors on prevalence of diabetes and to compare risk profiles of subjects with diabetes when defined by $\mathrm{HbA}_{1 \mathrm{c}}$ and glucose criteria. Subjects were recruited among participants in the longitudinal population-based Tromsø Study. $\mathrm{HbA}_{1 \mathrm{c}}$, fasting plasma glucose, and 2-hour plasma glucose were measured in 3,476 subjects. In total, 294 subjects met one or more of the diagnostic criteria for diabetes; 95 met the $\mathrm{HbA}_{1 \mathrm{c}}$ criterion only, 130 met the glucose criteria only, and 69 met both. Among subjects with diabetes detected by glucose criteria (regardless of $\mathrm{HbA}_{1 c}$ ), isolated raised 2-hour plasma glucose was more common in subjects aged $\geq 60$ years as compared to younger subjects and in elderly women as compared to elderly men. Subjects with diabetes detected by glucose criteria only had worse cardiometabolic risk profiles than those detected by $\mathrm{Hb}_{1 \mathrm{c}}$ only. In conclusion, the current $\mathrm{HbA}_{1 c}$ and glucose criteria defined different subjects with diabetes with only modest overlap. Among a substantial proportion of elderly subjects, and especially elderly women, the 2-hour plasma glucose was the only abnormal value.

\section{Introduction}

Criteria for the diagnosis of diabetes are based on measurements of fasting plasma glucose (FPG), 2-hour plasma glucose (2hPG), or haemoglobin $\mathrm{A}_{1 \mathrm{c}}\left(\mathrm{Hb}_{1 \mathrm{c}}\right)$. Single raised values with symptoms or raised values on two occasions of any one of these tests, or a combination of these tests can be used for diagnosis of diabetes $[1,2]$. The most commonly used test is the FPG as it is simple and inexpensive. The $2 \mathrm{hPG}$ is measured in combination with FPG in the oral glucose tolerance test (OGTT), where plasma glucose is measured in the morning after an overnight fast and 2 hours after oral ingestion of $75 \mathrm{~g}$ glucose. $\mathrm{HbA}_{1 \mathrm{c}}$ was recently introduced as a diagnostic test for diabetes. Compared to glucose measurements, $\mathrm{HbA}_{1 \mathrm{c}}$ has better sample stability, lower within-person variation and is independent of acute factors such as illness, recent food ingestion, stress, or exercise [3].

Diagnostic levels of FPG, $2 \mathrm{hPG}$, and $\mathrm{HbA}_{1 \mathrm{c}}$ are based on thresholds for increased risk of micro- and macrovascular disease, in particular retinopathy $[1,4]$. In the DETECT-2 study, sensitivity and specificity for prediction of prevalent retinopathy were almost equal when comparing FPG, 2hPG and $\mathrm{HbA}_{1 \mathrm{c}}$ [5]. Several recent studies have shown that both the prevalence of diabetes and the subjects diagnosed with diabetes vary when different diagnostic criteria for diabetes are applied [6-11]. According to current guidelines, clinicians can choose freely among FPG, OGTT, and $\mathrm{HbA}_{1 \mathrm{c}}$ when testing a patient for diabetes $[1,2]$. As $\mathrm{HbA}_{1 \mathrm{c}}$ and glucose criteria have been shown to identify different subjects with 
diabetes with relatively modest overlap, the choice of test may affect the test outcome $[6,7,9]$. This is important both at the individual level, where correct diagnosis, treatment, and prevention of later complications are in focus, and at the population level where early identification of the "correct" individuals at risk of developing complications is important for cost-effective utilisation of resources. Furthermore, race, age, and sex have been reported to affect the outcome of diabetes testing with different diagnostic criteria [6$8,12,13]$. This could have implications for the preferred choice of test in subgroups of patients. In Tromsø we have recently performed a large health survey where we measured $\mathrm{HbA}_{1 \mathrm{c}}, \mathrm{FPG}$, and $2 \mathrm{hPG}$ in 3,476 subjects without previously diagnosed diabetes. These data enabled us to study the effect of age, sex, and other factors on diabetes defined by different diagnostic criteria and to compare cardiometabolic risk profiles of subjects with diabetes defined by different criteria.

\section{Materials and Methods}

2.1. Subjects. Subjects were recruited from the sixth survey of the longitudinal population-based Troms $\varnothing$ Study performed by the University of Troms $ø$ from October 2007 to December 2008, where $\mathrm{HbA}_{1 \mathrm{c}}$ was measured in 12,769 participants. All subjects without self-reported diabetes and with $\mathrm{HbA}_{1 \mathrm{c}}$ in the range $5.8-6.9 \%$ and a random sample of approximately 200 subjects with $\mathrm{HbA}_{1 \mathrm{c}} 5.3 \%$ and $5.4 \%$ and 100 subjects with $\mathrm{HbA}_{1 \mathrm{c}} 5.5 \%, 5.6 \%$, and $5.7 \%$, respectively, were invited to participate in the Tromsø OGTT Study. Race was not registered, but practically all subjects were Caucasian.

2.2. Measurements. Waist and hip circumference, height, weight, and blood pressure were measured, body mass index (BMI) was defined, and physical activity score (PAS) was calculated as previously described [14]. $\mathrm{HbA}_{1 \mathrm{c}}$ was determined by high performance liquid chromatography (HPLC) using an automated analyser (Variant II, Bio-Rad Laboratories Inc., Hercules, CA, USA). The reference interval was 4.3-6.1\%. This analysis has been certified by the National Glycohemoglobin Standardization Program (NGSP) as having documented traceability to the Diabetes Control and Complication Trial (DCCT) reference method [15]. Haemoglobin (Hb) was measured by photometry using an automated analyser (reference intervals $11.5-16.0 \mathrm{~g} / \mathrm{dL}$ for women and 13.0-17.0 g/dL for men). Plasma glucose, serum insulin, and serum C-peptide were measured and analysed as previously described [14]. Serum triglyceride (TG) was analysed with an enzymatic colorimetric assay using an automated clinical chemistry analyser (reference interval 0.5-2.6 mmol/L). Estimates of insulin sensitivity in the fasting state were calculated using homeostasis model assessment (HOMA-IR) and the Quantitative Insulin-Sensitivity Check Index (QUICKI) [16, 17], and insulin sensitivity including the 2-hour values for glucose and insulin with the insulin sensitivity index $\left(\mathrm{ISI}_{0.120}\right)$ according to the formula by Gutt et al. [ $(m / M P G) / \log$ MSI, where $m=(75000 \mathrm{mg}+$ [fasting glucose $(\mathrm{mg} / \mathrm{dL})-2$ $\mathrm{h}$ glucose $(\mathrm{mg} / \mathrm{dL})] \times 0.19 \times$ body weight $(\mathrm{kg})) / 120 \mathrm{~min}$,
$\mathrm{MPG}=$ mean of fasting and $2-\mathrm{h}$ glucose concentrations $(\mathrm{mmol} / \mathrm{L}) ; \mathrm{MSI}=$ mean of fasting and $2-\mathrm{h}$ insulin concentrations (milliunits per liter)] [18].

OGTTs were performed from February 2008 until August 2010 as previously described [14]. All OGTTs were performed in the morning after an overnight fast. To minimize time between OGTT and $\mathrm{HbA}_{1 \mathrm{c}}$, the latter was measured simultaneously with the OGTT from September 2008 onwards. $\mathrm{HbA}_{1 \mathrm{c}}$ from the Tromsø Study 2007-2008 was used for the 932 participants who completed OGTT before September 2008. Mean change in $\mathrm{HbA}_{1 \mathrm{c}}$ for the 2,544 subjects who measured $\mathrm{HbA}_{1 \mathrm{c}}$ on both occasions was $-0.03 \pm 0.3 \%$. For the purpose of this study, we chose to classify subjects with a single value of FPG $\geq 7.0 \mathrm{mmol} / \mathrm{L}$, $2 \mathrm{hPG} \geq 11.1 \mathrm{mmol} / \mathrm{L}$, and/or $\mathrm{HbA}_{1 \mathrm{c}} \geq 6.5 \%$ as having diabetes, even though subjects were asymptomatic. Subjects with diabetes were subdivided into diabetes detected by $\mathrm{HbA}_{1 \mathrm{c}}$ only, by OGTT (raised FPG and/or 2hPG) only and by both. Furthermore, subjects with diabetes detected by OGTT (regardless of $\mathrm{HbA}_{1 \mathrm{c}}$ ) were subdivided into diabetes detected by FPG (regardless of $2 \mathrm{hPG}$ ) and by isolated raised $2 \mathrm{hPG}$.

2.3. Statistics. Normal distribution was evaluated by visual inspection of histograms and determination of skewness and kurtosis, and after natural log transformation of TG, PAS, QUICKI, HOMA-IR, and ISI $_{0.120}$, all variables except the PAS (where several subjects had "0" values) were considered normally distributed. Ln values were used when these variables were dependent variables. Pearson Chi-square test was used for subgroup analysis in Table 2. Comparisons between groups were performed with logistic regression for categorical variables and univariate analysis of variance with Bonferroni post hoc adjustment or Mann Whitney $U$ test for continuous variables in Table 3. Venn diagrams were constructed to illustrate overlap between diagnostic criteria and scatterplots to illustrate the distribution of FPG and $2 \mathrm{hPG}$ values in relation to $\mathrm{HbA}_{1 \mathrm{c}}$. Unless otherwise stated, data are expressed as mean \pm SD for normally distributed values and as median (5, 95 percentile) for non-normally distributed values. All tests were two-sided, and $P$ value $<$ 0.05 was considered statistically significant. The Statistical Package for Social Sciences version 17.0 was used for all statistical analyses (SPSS Inc., Chicago, IL, USA).

\section{Results}

Among the 4,393 subjects who were invited, 3,520 attended and 3,476 completed the OGTT. The number of subjects planned to participate, invited to OGTT, and attended at different $\mathrm{HbA}_{1 \mathrm{c}}$ levels, as measured in the Tromsø Study 2007-2008, is presented in Table 1. In total, 294 (8.5\%) subjects met one or more of the diagnostic criteria for diabetes. Mean age was 61 years and $49.5 \%$ were women.

\subsection{Prevalence of Diabetes Defined by Different Diagnostic} Criteria. Among those who completed OGTT, 164 (4.7\%) met the $\mathrm{HbA}_{1 \mathrm{c}}$ criterion, 119 (3.4\%) met the FPG criterion, and $126(3.6 \%)$ met the $2 \mathrm{hPG}$ criterion. In total 199 (5.7\%) 
TABle 1: Number of participants planned to participate, invited to participate, attended, and completed OGTT in the Tromsø OGTT Study.

\begin{tabular}{|c|c|c|c|c|}
\hline \multirow{2}{*}{$\begin{array}{l}\mathrm{HbA}_{1 \mathrm{c}} \text { level in the sixth Tromsø } \\
\text { study survey (2007-2008) }\end{array}$} & \multicolumn{4}{|c|}{ Number of subjects } \\
\hline & Planned to participate & Invited to participate & Attended OGTT & Completed OGTT \\
\hline $5.3 \%$ & 200 & 309 & 180 & 176 \\
\hline $5.4 \%$ & 200 & 308 & 195 & 194 \\
\hline $5.5 \%$ & 100 & 144 & 109 & 107 \\
\hline $5.6 \%$ & 100 & 164 & 128 & 123 \\
\hline $5.7 \%$ & 100 & 157 & 115 & 112 \\
\hline $5.8-6.9 \%$ & All & 3311 & 2793 & 2764 \\
\hline Total & & 4393 & 3520 & 3476 \\
\hline
\end{tabular}

Abbreviations: Haemoglobin $\mathrm{A}_{1 \mathrm{c}}, \mathrm{HbA}_{1 c}$; oral glucose tolerance test, OGTT.

The table summarises how many subjects were planned to participate in the OGTT Study, how many were invited to OGTT, how many attended, and how many who completed OGTT at different $\mathrm{HbA}_{1 \mathrm{c}}$ levels and in total.

met the OGTT (FPG and/or 2hPG) criteria. As presented in Table 2, $95(32.3 \%)$ of those with diabetes met the $\mathrm{HbA}_{1 \mathrm{c}}$ criterion only, $130(44.2 \%)$ met the OGTT criteria only, and $69(23.5 \%)$ met both criteria. The overlap between subjects with diabetes defined by $\mathrm{HbA}_{1 \mathrm{c}}$ and OGTT varied between $10-35 \%$ in different subgroups.

$\mathrm{HbA}_{1 \mathrm{c}}$ alone detected more subjects with diabetes as compared to OGTT alone in those with BMI $<25 \mathrm{~kg} / \mathrm{m}^{2}$, TG $<1.2 \mathrm{mmol} / \mathrm{L}$, and high PAS, but there were no significant differences in subgroup analysis of age and sex (Table 2). Among those with diabetes detected by OGTT (regardless of $\mathrm{HbA}_{1 \mathrm{c}}$ ), isolated raised $2 \mathrm{hPG}$ was more common in subjects aged $\geq 60$ years and women (Table 2). This effect of age and sex was not due to differences in BMI. Stratification for age showed that the sex difference was significant only in those aged $\geq 60$ years, where $58 \%$ of women and $36 \%$ of men had isolated raised $2 \mathrm{hPG}(P<0.01)$. Mean age and BMI did not differ significantly between men and women. Furthermore, the sex difference was significant only in the two lower BMI groups $(P<0.05)$ and in the lowest PAS tertile $(P<0.05)$.

The distribution of subjects with diabetes detected by $\mathrm{HbA}_{1 \mathrm{c}}$ only, OGTT only, and both, as well as by OGTT components (FPG and isolated raised 2hPG) is illustrated stratified for age and sex in Figure 1. The overlap between subjects with diabetes defined by $\mathrm{HbA}_{1 \mathrm{c}}$ and OGTT was relatively consistent, but prevalence of isolated raised $2 \mathrm{hPG}$ was higher in subjects aged $\geq 60$ years as compared to younger subjects, and in elderly women as compared to elderly men. In subjects aged $\geq 60$ years the distribution of $2 \mathrm{hPG}$ values in relation to $\mathrm{HbA}_{1 \mathrm{c}}$ values was more scattered as compared to younger subjects (Figure 2), illustrating that for many subjects in this age group an $\mathrm{HbA}_{1 \mathrm{c}}$ value $<6.5 \% \mathrm{did}$ not exclude a $2 \mathrm{hPG}$ value above the cut off point for diabetes.

3.2. Characteristics of Subjects with Diabetes Defined by Different Diagnostic Criteria. As presented in Table 3, subjects with diabetes detected by $\mathrm{HbA}_{1 \mathrm{c}}$ only had lower TG, lower systolic blood pressure, higher insulin sensitivity and were less insulin resistant and more physically active as compared to subjects with diabetes detected by OGTT only. Among subjects with diabetes detected by OGTT (regardless of $\mathrm{HbA}_{1 \mathrm{c}}$ ), those with raised FPG differed from those with isolated raised $2 \mathrm{hPG}$ by being younger, predominantly men and more insulin resistant (Table 3).

\section{Discussion}

4.1. Prevalence of Diabetes Defined by Different Diagnostic Criteria. In our population, we found prevalence of diabetes detected by OGTT only to be higher than prevalence of diabetes detected by $\mathrm{HbA}_{1 \mathrm{c}}$ only. The present study also confirmed results from recent studies showing that $\mathrm{HbA}_{1 \mathrm{c}}$ and OGTT define different subjects with diabetes with relatively modest overlap, which in our study was only $23.5 \%[6,7,9]$. Prevalence of diabetes defined by $\mathrm{HbA}_{1 c}$ and OGTT, and overlap between these, differs in previous studies, probably due to differences in age, race, and sex composition of the populations and/or lack of standardisation of $\mathrm{HbA}_{1 \mathrm{c}}$ and glucose measurements [7, 8, 12, 13, 19].

Race, age, and sex have been reported to affect the outcome of diabetes testing with different diagnostic criteria $[6-8,12,13]$. Our study population did not allow us to study the effect of race as practically all subjects were Caucasian. When comparing subjects aged $\geq 60$ years with younger subjects, we found no difference in prevalence of diabetes detected by $\mathrm{HbA}_{1 \mathrm{c}}$ only and OGTT only. Among those with diabetes detected by OGTT (regardless of $\mathrm{HbA}_{1 \mathrm{c}}$ ), prevalence of isolated raised $2 \mathrm{hPG}$ was higher in older ( $\geq 60$ years) as compared to younger subjects. Furthermore, we found that among subjects aged $\geq 60$ years, having a $2 \mathrm{hPG}$ in the diabetic range but a nondiabetic $\mathrm{HbA}_{1 \mathrm{c}}$ value was more common as compared to younger subjects. Similarly, in the Finnish population-based cross sectional FIN-D2D study including 2,826 men and women aged 45-74 years, any given $\mathrm{HbA}_{1 \mathrm{c}}$ value was found to imply a much higher $2 \mathrm{hPG}$ and slightly lower FPG in elderly as compared to middle aged subjects [13]. The $2 \mathrm{hPG}$ is known to increase more with age than FPG $[20,21]$. Possible explanations for the increased prevalence of isolated raised $2 \mathrm{hPG}$ among elderly subjects could be reduced basal insulin secretion [22], delayed insulin response after oral glucose intake [21], physical inactivity, and/or weight gain [23].

In our data, there was no sex difference in diabetes detected by $\mathrm{HbA}_{1 \mathrm{c}}$ only and OGTT only. However, we found 


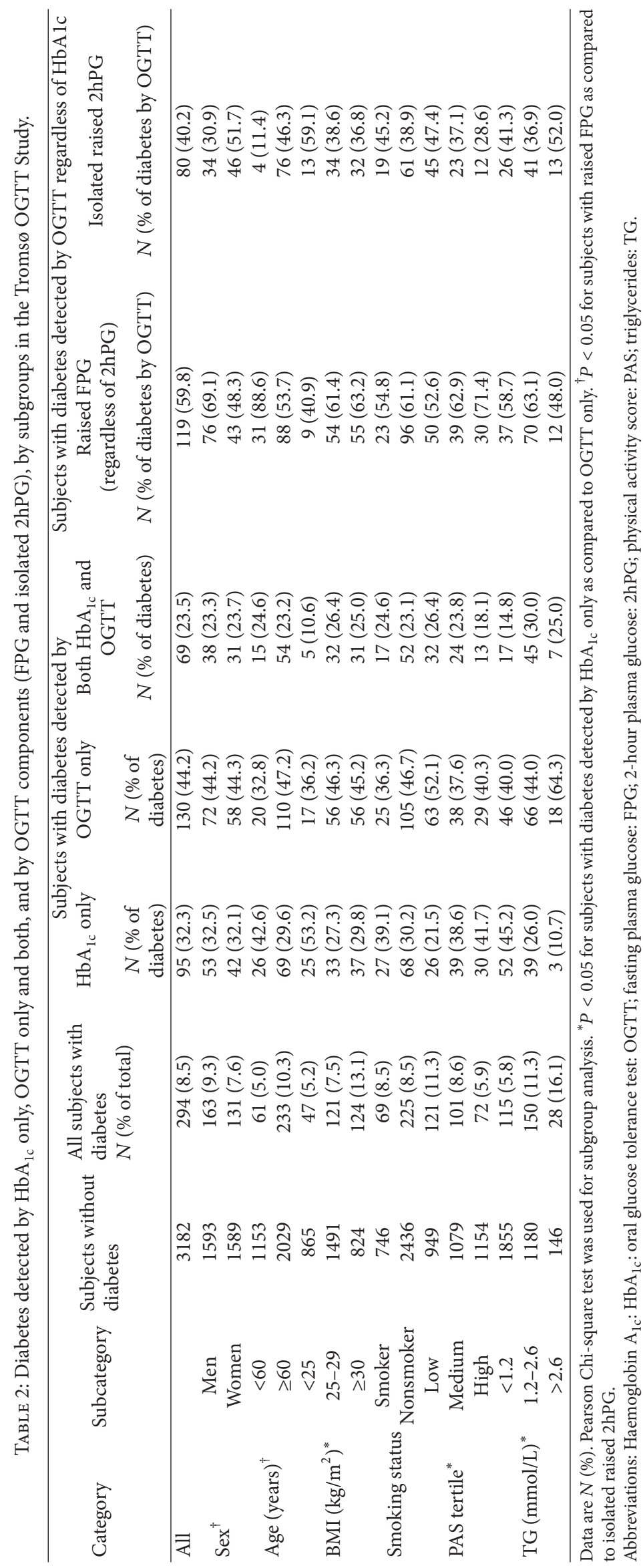




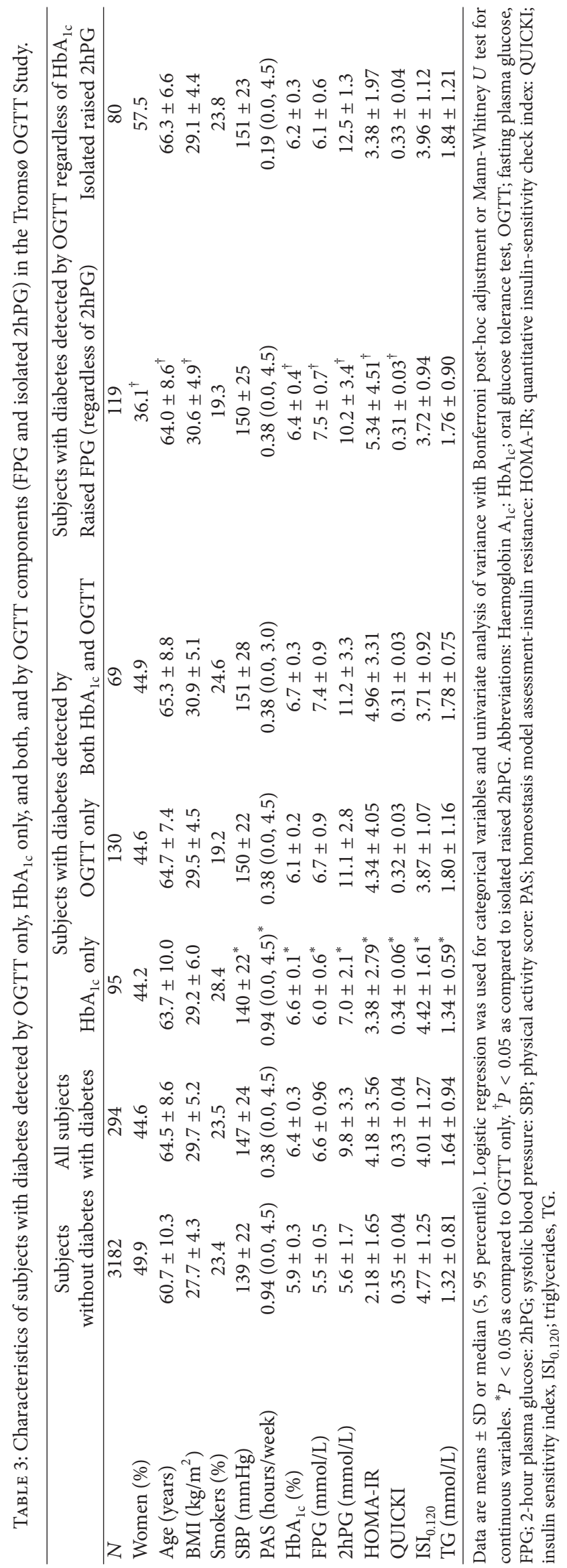




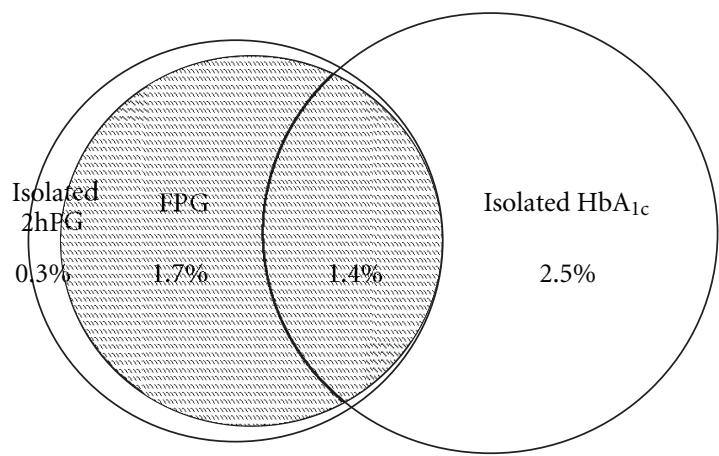

(a)

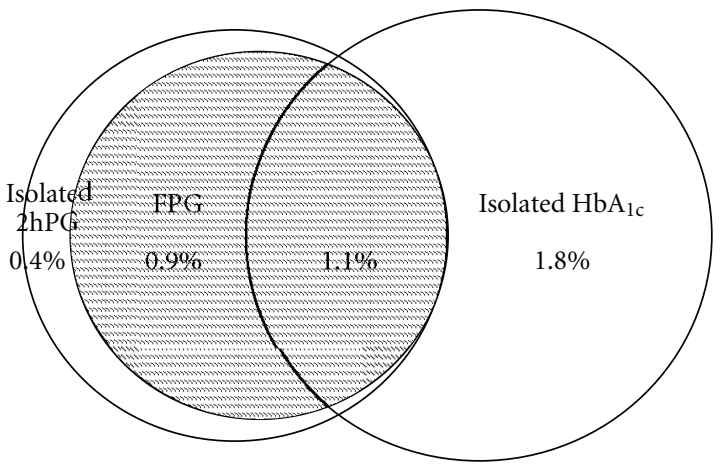

(c)

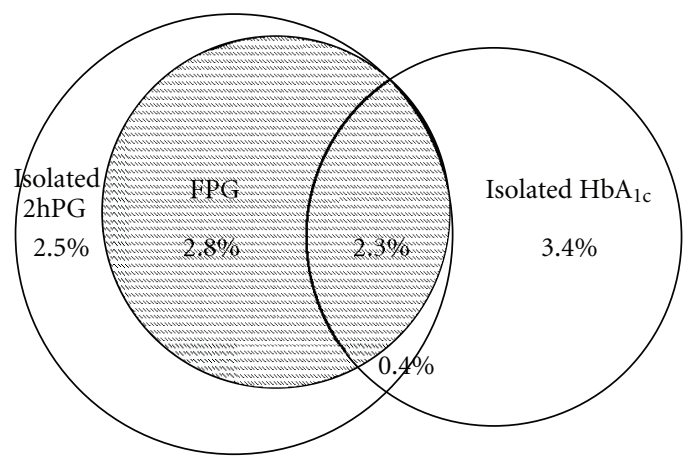

(b)

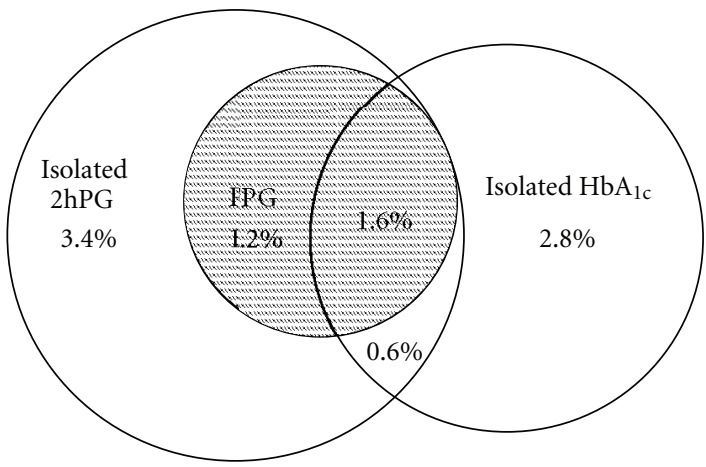

(d)

FIGURE 1: Diabetes prevalence by different diagnostic criteria. Venn diagrams illustrating prevalence of diabetes (\%) defined by OGTT criteria (FPG and isolated raised $2 \mathrm{hPG}$ ) and $\mathrm{HbA}_{1 \mathrm{c}}$ in (a) men aged $<60$ years; (b) men aged $\geq 60$ years; (c) women aged $<60$ years; (d) women $\geq 60$ years. The Tromsø OGTT Study.
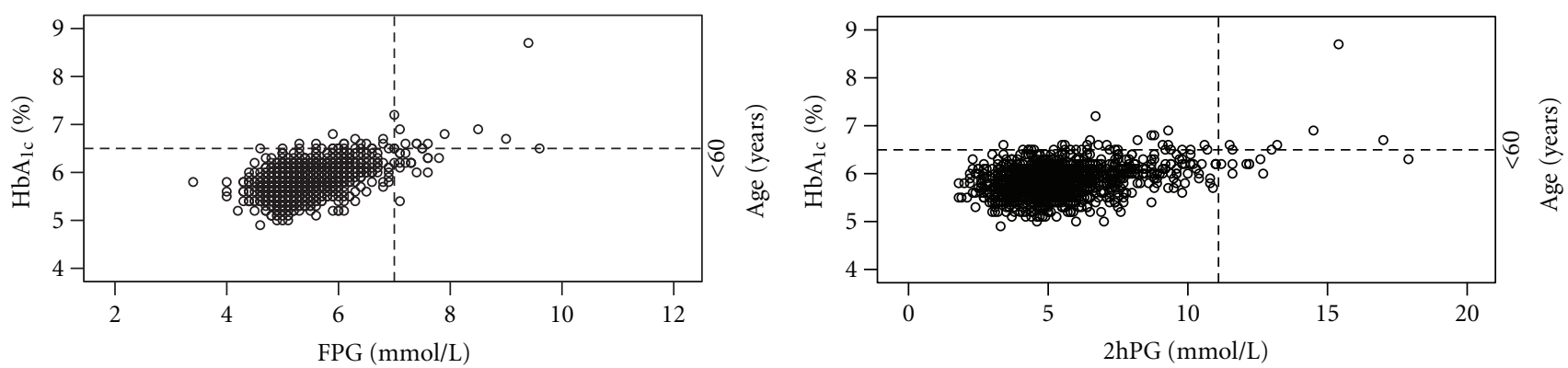

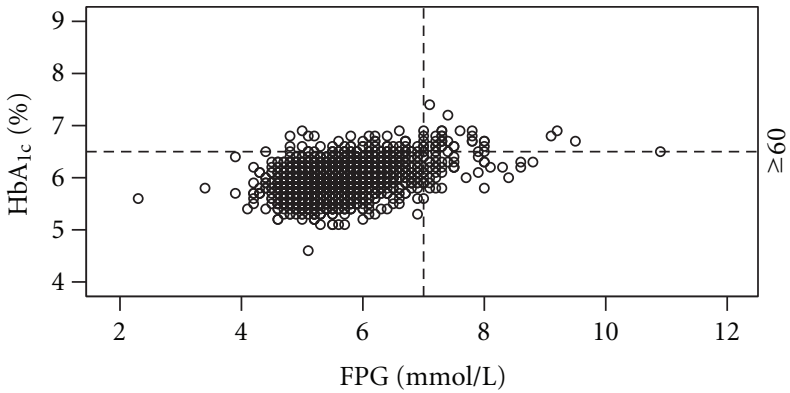

(a)

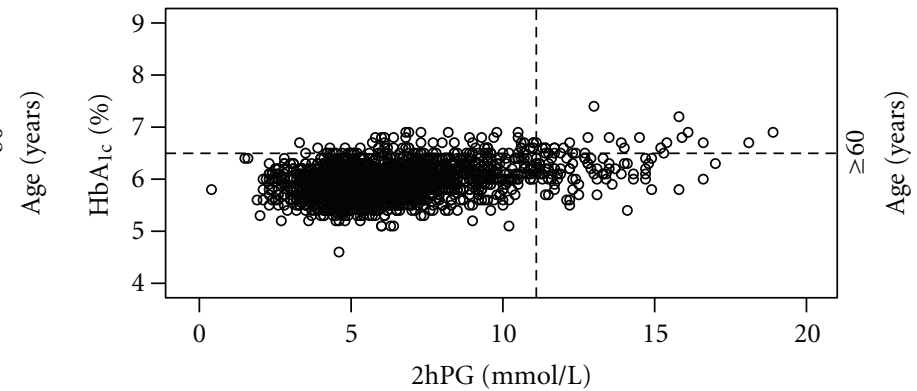

(b)

FIGURE 2: Distribution of FPG and $2 \mathrm{hPG}$ values in relation to $\mathrm{HbA}_{1 \mathrm{c}}$. Scatterplots illustrating the distribution of (a) FPG and (b) $2 \mathrm{hPG}$ values in relation to $\mathrm{HbA}_{1 \mathrm{c}}$ in subjects aged $<60$ years and subjects aged $\geq 60$ years. Stippled lines show cut-off points for diabetes. The Troms $\emptyset$ OGTT Study. 
that among those with diabetes detected by OGTT (regardless of $\mathrm{HbA}_{1 \mathrm{c}}$ ), isolated raised $2 \mathrm{hPG}$ was more common in elderly women as compared to elderly men, a difference that could not be explained by differences in age or BMI. Similarly, the FIN-D2D study reported that $\mathrm{HbA}_{1 \mathrm{c}}$ tends to miss more elderly diabetic people and especially women [13]. Previous studies have suggested that differences in FPG and $\mathrm{HbA}_{1 \mathrm{c}}$ levels are likely to reflect sex-specific differences in glucose regulation as they, unlike differences in $2 \mathrm{hPG}$, remained after adjusting for height and body composition [24, 25]. We also found that $\mathrm{HbA}_{1 \mathrm{c}}$ alone detected more subjects with diabetes as compared to OGTT alone in subjects with BMI $<25 \mathrm{~kg} / \mathrm{m}^{2}$ as compared to those with higher BMI. In a recently published paper, we reported that a particular $\mathrm{HbA}_{1 \mathrm{c}}$ value implied relatively higher $2 \mathrm{hPG}$ and FPG in subjects with high BMI compared to subjects with lower BMI [14]. As very few reports have addressed this issue, it remains uncertain whether BMI has an effect on diagnosis of diabetes by different criteria.

4.2. Characteristics of Subjects with Diabetes Defined by Different Diagnostic Criteria. In our population, subjects with diabetes detected by OGTT only had a worse cardiometabolic risk profile than those detected by $\mathrm{HbA}_{1 \mathrm{c}}$ only. Previous studies have shown conflicting results; some have found the worst risk profiles in subjects with diabetes defined by OGTT $[6,8,9]$, some in subjects with diabetes defined by $\mathrm{HbA}_{1 \mathrm{c}}$ [26], and some have found the two groups to have equally unfavourable risk profiles $[8,10]$. In the international A1C-Derived Average Glucose study including 427 subjects with diabetes, $\mathrm{HbA}_{1 \mathrm{c}}$, FPG, and $2 \mathrm{hPG}$ were all associated with CVD risk factors, but the strongest association was seen with $\mathrm{HbA}_{1 \mathrm{c}}$ [27]. We did not have data to evaluate the risk of diabetes complications in the different groups. Although both $\mathrm{HbA}_{1 \mathrm{c}}$ and $2 \mathrm{hPG}$ have been shown to be independent risk factors for cardiovascular morbidity and mortality, the added prognostic information may be marginal as compared to standard nonglycaemic risk factors [28-30]. In a prospective study based on the Norwegian populationbased longitudinal HUNT study, the risk of macrovascular complications in subjects with relatively low $\mathrm{HbA}_{1 \mathrm{c}}$ values was found to be mainly related to conventional risk factors [31].

The strength of our study is that OGTT was performed in a large number of subjects recruited from a population representative of the general population in our area. The main shortcomings of our study are that only subjects with $\mathrm{HbA}_{1 \mathrm{c}}$ in the range of $5.3-6.9 \%$ were invited to participate and that subjects included at an early stage of the study did not have $\mathrm{HbA}_{1 \mathrm{c}}$ measured simultaneously with the OGTT, but were included in the analysis with the $\mathrm{HbA}_{1 \mathrm{c}}$ value measured in the Tromsø Study 2007-2008. We chose to include these subjects in the analysis as we found that change in $\mathrm{HbA}_{1 \mathrm{c}}$ from the Tromsø Study to the OGTT visit was negligible for those who had $\mathrm{HbA}_{1 \mathrm{c}}$ measured at both occasions. Furthermore, in the absence of clear symptoms, diagnosis of diabetes requires raised values of $\mathrm{HbA}_{1 \mathrm{c}}$, FPG, or $2 \mathrm{hPG}$ on two occasions. For practical reasons, we did not repeat either $\mathrm{HbA}_{1 \mathrm{c}}$, or the
OGTTs, but chose to classify subjects with a single raised value of $\mathrm{HbA}_{1 \mathrm{c}}$, FPG, or $2 \mathrm{hPG}$ as having diabetes. As FPG, and especially $2 \mathrm{hPG}$, are known to have high within-person variation, repeating the OGTTs to confirm the diagnosis would probably have reduced the number of subjects with diabetes detected by OGTT [32]. $\mathrm{HbA}_{1 \mathrm{c}}$ is known to be affected by anaemia. Hb was measured in the Tromsø Study 2007-2008, but not simultaneously as OGTT. However, anaemia is not a source of error when analysing $\mathrm{HbA}_{1 \mathrm{c}}$ with the HPLC method used in our study as the analysis is not performed if there are too few or too many erythrocytes in the sample. Haemolytic anaemia could result in falsely low $\mathrm{HbA}_{1 \mathrm{c}}$, but the condition is rare in our population and is not likely to affect the results. Other shortcomings are that we did not have information about retinopathy or other end organ diseases, and that we did not differentiate between type 1 and type 2 diabetes. However, as subjects in our study did not have previously diagnosed diabetes and age ranged from 30-87 years, most diabetes cases were likely to be type 2 diabetes. The cross-sectional study design is a major limitation when evaluating the impact of using different diagnostic criteria for diabetes. Prospective studies are needed to clarify which test detects the population with the highest risk of disease progression and complications of diabetes.

\section{Conclusions}

The current $\mathrm{HbA}_{1 \mathrm{c}}$ and glucose criteria for diabetes defined different subjects with only modest overlap. Among those with diabetes detected by OGTT (regardless of $\mathrm{HbA}_{1 \mathrm{c}}$ ), isolated raised 2-hour plasma glucose was more common in subjects aged $\geq 60$ years as compared to younger subjects, and in elderly women as compared to elderly men. As race, age, sex, and possibly BMI seem to affect $\mathrm{HbA}_{1 \mathrm{c}}$, FPG, and $2 \mathrm{hPG}$ and the relationship between these, creating an algorithm for choice of diagnostic test in different subgroups is a possibility and may be beneficial. If the aim is to detect as many patients with diabetes as possible, our data suggest that OGTT would be preferable for those aged $\geq 60$ years, and especially women, while $\mathrm{HbA}_{1 \mathrm{c}}$ would be preferable for the younger and those with low BMI. However, in order to decide which diagnostic test should be preferred, and whether race, age, sex, and/or BMI specific guidelines should be considered, prospective studies with micro- and macrovascular endpoints are needed.

\section{Abbreviations}

$\begin{array}{ll}\text { Hb: } & \text { Haemoglobin } \\ \text { HbA }_{1 \mathrm{c}}: & \text { Haemoglobin } \mathrm{A}_{1 \mathrm{c}} \\ \text { OGTT: } & \text { Oral glucose tolerance test } \\ \text { FPG: } & \text { Fasting plasma glucose } \\ \text { 2hPG: } & \text { 2-hour plasma glucose } \\ \text { HPLC: } & \text { High precision liquid chromatography } \\ \text { BMI: } & \text { Body mass index } \\ \text { HOMA-IR: Homeostasis model assessment-insulin } & \begin{array}{l}\text { resistance } \\ \text { QUICKI: }\end{array} \\ & \begin{array}{l}\text { Quantitative insulin-sensitivity check } \\ \text { index }\end{array}\end{array}$


ISI $_{0.120}$ : Insulin sensitivity index,

PAS: Physical activity score

TG: Triglycerides.

\section{Ethical Approval}

The study was approved by the Regional Committee for Medical and Health Research Ethics, North Norway. All participants gave written informed consent prior to the study.

\section{Conflict of Interests}

No potential conflict of interests relevant to this paper was reported.

\section{Authors' Contribution}

M. S. Hutchinson gathered and researched data and wrote the paper. R. M. Joakimsen contributed to the discussion and reviewed the paper. I. Njølstad was responsible for the Tromsø Study data and reviewed the paper. H. Schirmer contributed to the discussion and reviewed the paper. Y. Figenschau was responsible for the laboratory analyses and reviewed the paper. J. Svartberg contributed to the discussion and reviewed the paper. R. Jorde led the Tromsø OGTT Study, contributed to the discussion and reviewed the paper.

\section{Acknowledgments}

The superb assistance provides by study nurse Anita Korsberg and the staff at the Clinical Research Unit at the University Hospital of North Norway as well as the staff at the Division of Laboratory Medicine, University Hospital of North Norway, is gratefully acknowledged. The present study was supported by a grant from The Northern Norway Regional Health Authority and the Research Council of Norway.

\section{References}

[1] World Health Organization, Use of Glycated Haemoglobin (HbA1c) in the Diagnosis of Diabetes Mellitus: Abbreviated Report of a WHO Consultation, World Health Organization, Geneva, Switzerland, 2011.

[2] American Diabetes Association, "Diagnosis and classification of diabetes mellitus," Diabetes Care, vol. 35, supplement 1, pp. S64-S71, 2012.

[3] D. B. Sacks, “A1C versus glucose testing: a comparison," Diabetes Care, vol. 34, no. 2, pp. 518-523, 2011.

[4] "Report of the expert committee on the diagnosis and classification of diabetes mellitus," Diabetes Care, vol. 20, no. 7, pp. 1183-1197, 1997.

[5] S. Colagiuri, C. M. Y. Lee, T. Y. Wong, B. Balkau, J. E. Shaw, and K. Borch-Johnsen, "Glycemic thresholds for diabetes-specific retinopathy: implications for diagnostic criteria for diabetes," Diabetes Care, vol. 34, no. 1, pp. 145-150, 2011.

[6] W. Rathmann, B. Kowall, T. Tamayo et al., "Hemoglobin A1c and glucose criteria identify different subjects as having type 2 diabetes in middle-aged and older populations: The KORA
S4/F4 Study," Annals of Internal Medicine, vol. 44, no. 2, pp. 170-177, 2012.

[7] C. C. Cowie, K. F. Rust, D. D. Byrd-Holt et al., "Prevalence of diabetes and high risk for diabetes using A1C criteria in the U.S. population in 1988-2006," Diabetes Care, vol. 33, no. 3, pp. 562-568, 2010.

[8] R. Borg, D. Vistisen, D. R. Witte, and K. Borch-Johnsen, "Comparing risk profiles of individuals diagnosed with diabetes by OGTT and HbAlcThe Danish Inter99 study," Diabetic Medicine, vol. 27, no. 8, pp. 906-910, 2010.

[9] S. A. Mostafa, M. J. Davies, D. Webb et al., “The potential impact of using glycated haemoglobin as the preferred diagnostic tool for detecting Type 2 diabetes mellitus," Diabetic Medicine, vol. 27, no. 7, pp. 762-769, 2010.

[10] E. Cosson, M. T. Nguyen, E. Hamo-Tchatchouang et al., "What would be the outcome if the American Diabetes Association recommendations of 2010 had been followed in our pratice in 1998-2006?" Diabetic Medicine, vol. 28, no. 5, pp. 567-574, 2011.

[11] C. Lorenzo and S. M. Haffner, "Performance characteristics of the new definition of diabetes: the insulin resistance atherosclerosis study," Diabetes Care, vol. 33, no. 2, pp. 335-337, 2010.

[12] D. L. Christensen, D. R. Witte, L. Kaduka et al., "Moving to an A1C-based diagnosis of diabetes has a different impact on prevalence in different ethnic groups," Diabetes Care, vol. 33, no. 3, pp. 580-582, 2010.

[13] J. T. Saltevo, H. Kautiainen, L. Niskanen et al., "Ageing and associations of fasting plasma glucose and $2 \mathrm{~h}$ plasma glucose with $\mathrm{HbA}(1 \mathrm{C})$ in apparently healthy population., "FIN-D2D" study," Diabetes Research and Clinical Practice Journal, vol. 93, pp. 344-349, 2011.

[14] M. S. Hutchinson, R. M. Joakimsen, I. Njolstad, H. Schirmer, Y. Figenschau, and R. Jorde, "Haemoglobin A1c in diagnosis of diabetes mellitus and pre-diabetes, validation by oral glucose tolerance test. The Tromso OGTT Study," Journal of Endocrinological Investigation, vol. 35, no. 9, pp. 835-840, 2012.

[15] R. R. Little, C. L. Rohlfing, and D. B. Sacks, "Status of hemoglobin A1c measurement and goals for improvement: from Chaos to order for improving diabetes care," Clinical Chemistry, vol. 57, no. 2, pp. 205-214, 2011.

[16] A. Katz, S. S. Nambi, K. Mather et al., "Quantitative insulin sensitivity check index: a simple, accurate method for assessing insulin sensitivity in humans," Journal of Clinical Endocrinology and Metabolism, vol. 85, no. 7, pp. 2402-2410, 2000.

[17] D. R. Matthews, J. P. Hosker, A. S. Rudenski, B. A. Naylor, D. F. Treacher, and R. C. Turner, "Homeostasis model assessment: Insulin resistance and $\beta$-cell function from fasting plasma glucose and insulin concentrations in man," Diabetologia, vol. 28, no. 7, pp. 412-419, 1985.

[18] M. Gutt, C. L. Davis, S. B. Spitzer et al., "Validation of the insulin sensitivity index (ISI0,120): comparison with other measures," Diabetes Research and Clinical Practice, vol. 47, no. 3, pp. 177-184, 2000.

[19] "International Expert Committee report on the role of the A1C assay in the diagnosis of diabetes," Diabetes Care, vol. 32, pp. 1327-1334, 2009.

[20] "Consequences of the new diagnostic criteria for diabetes in older men and women: The DECODE Study (Diabetes Epidemiology: Collaborative Analysis of Diagnostic Criteria in Europe)," Diabetes Care, vol. 22, no. 10, pp. 1667-1671, 1999.

[21] M. B. Davidson, "The effect of aging on carbohydrate metabolism: a review of the English literature and a practical 
approach to the diagnosis of diabetes mellitus in the elderly," Metabolism: Clinical and Experimental, vol. 28, no. 6, pp. 688-705, 1979.

[22] P. Iozzo, H. Beck-Nielsen, M. Laakso, U. Smith, H. YkiJärvinen, and E. Ferrannini, "Independent influence of age on basal insulin secretion in nondiabetic humans," Journal of Clinical Endocrinology and Metabolism, vol. 84, no. 3, pp. 863-868, 1999.

[23] P. Imbeault, J. B. Prins, M. Stolic et al., "Aging per se does not influence glucose homeostasis: in vivo and in vitro evidence," Diabetes Care, vol. 26, no. 2, pp. 480-484, 2003.

[24] K. Færch, K. Borch-Johnsen, A. Vaag, T. Jørgensen, and D. R. Witte, "Sex differences in glucose levels: a consequence of physiology or methodological convenience? the Inter99 study," Diabetologia, vol. 53, no. 5, pp. 858-865, 2010.

[25] R. A. Sicree, P. Z. Zimmet, D. W. Dunstan, A. J. Cameron, T. A. Welborn, and J. E. Shaw, "Differences in height explain gender differences in the response to the oral glucose tolerance test-The AusDiab study," Diabetic Medicine, vol. 25, no. 3, pp. 296-302, 2008.

[26] M. Boronat, P. Saavedra, L. Lopez-Rios, M. Riano, A. M. Wagner, and F. J. Nóvoa, "Differences in cardiovascular risk profile of diabetic subjects discordantly classified by diagnostic criteria based on glycated hemoglobin and oral glucose tolerance test," Diabetes Care, vol. 33, no. 12, pp. 2671-2673, 2010.

[27] R. Borg, J. C. Kuenen, B. Carstensen et al., "HbA1cand mean blood glucose show stronger associations with cardiovascular disease risk factors than do postprandial glycaemia or glucose variability in persons with diabetes: The A1C-Derived Average Glucose (ADAG) study," Diabetologia, vol. 54, no. 1, pp. 69-72, 2011.

[28] K. T. Khaw, N. Wareham, S. Bingham, R. Luben, A. Welch, and N. Day, "Association of hemoglobin A1c with cardiovascular disease and mortality in adults: The European prospective investigation into cancer in Norfolk," Annals of Internal Medicine, vol. 141, no. 6, pp. 413-420, 2004.

[29] J. B. Meigs, D. M. Nathan, R. B. D’Agostino, and P. W. F. Wilson, "Fasting and postchallenge glycemia and cardiovascular disease risk: the framingham offspring study," Diabetes Care, vol. 25, no. 10, pp. 1845-1850, 2002.

[30] The DECODE Study Group, "Glucose tolerance and cardiovascular mortality: comparison of fasting and 2-hour diagnostic criteria," Archives of Internal Medicine, vol. 161, pp. 397-405, 2001.

[31] A. C. Dale, K. Midthjell, T. I. Nilsen, R. Wiseth, and L. J. Vatten, "Glycaemic control in newly diagnosed diabetes patients and mortality from ischaemic heart disease: 20-year follow-up of the HUNT Study in Norway," European Heart Journal, vol. 30, no. 11, pp. 1372-1377, 2009.

[32] E. Selvin, C. M. Crainiceanu, F. L. Brancati, and J. Coresh, "Short-term variability in measures of glycemia and implications for the classification of diabetes," Archives of Internal Medicine, vol. 167, no. 14, pp. 1545-1551, 2007. 


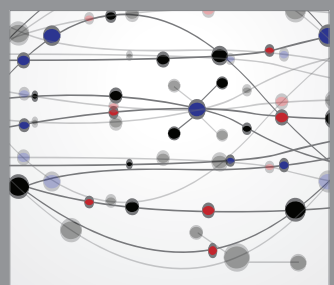

The Scientific World Journal
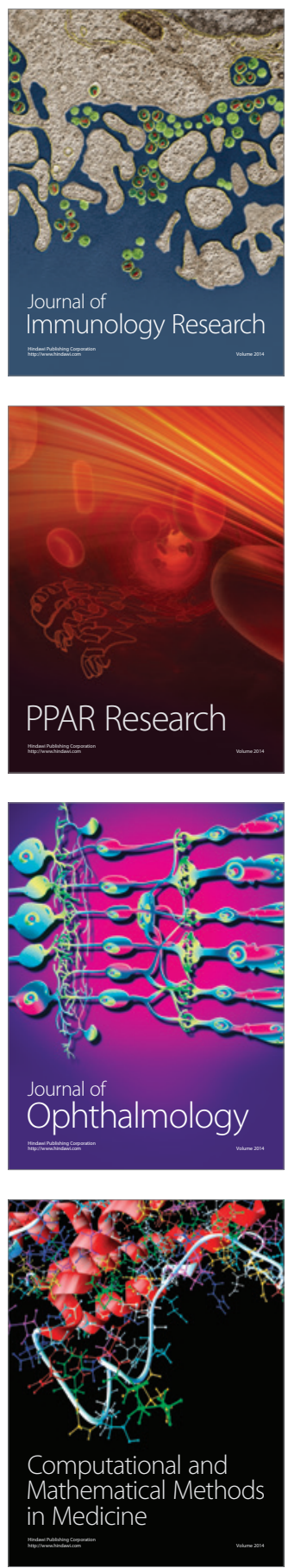

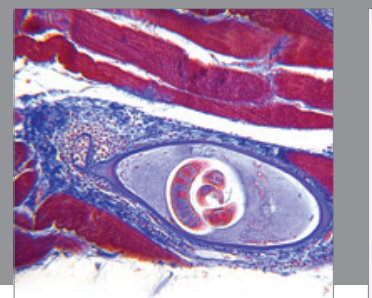

Gastroenterology

Research and Practice
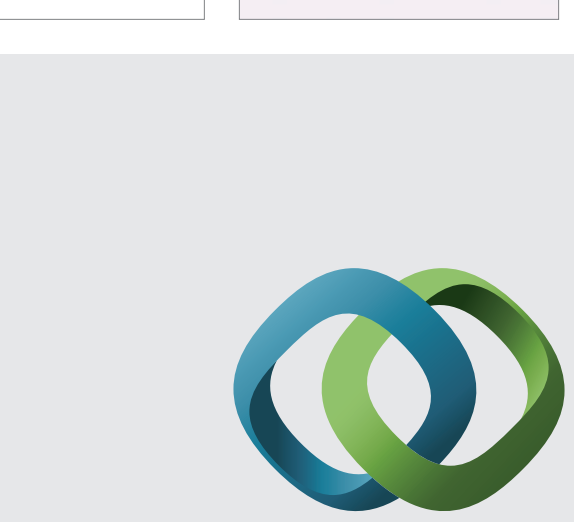

\section{Hindawi}

Submit your manuscripts at

http://www.hindawi.com
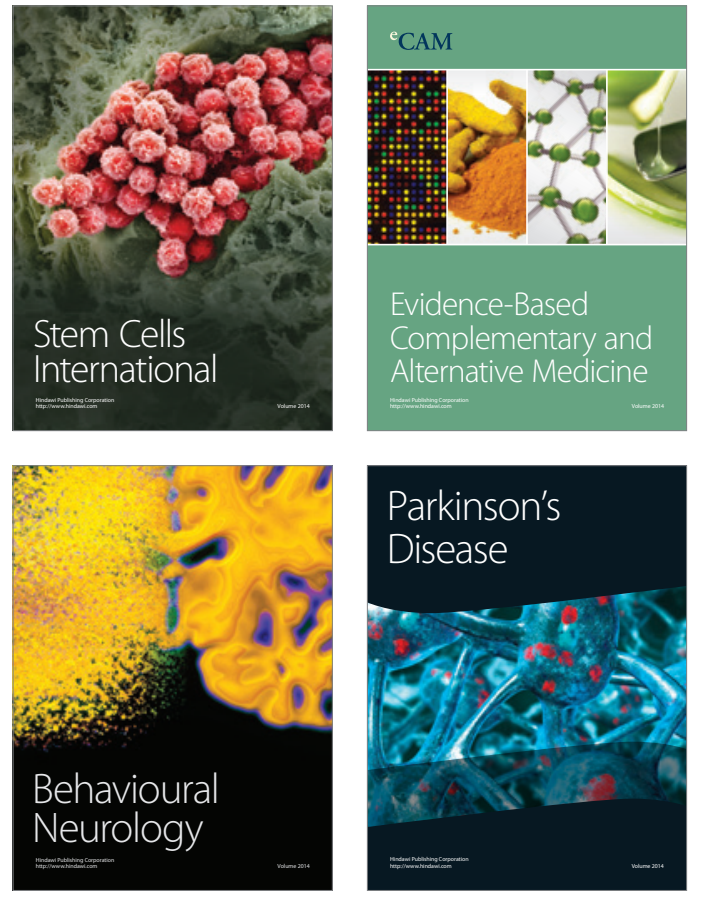
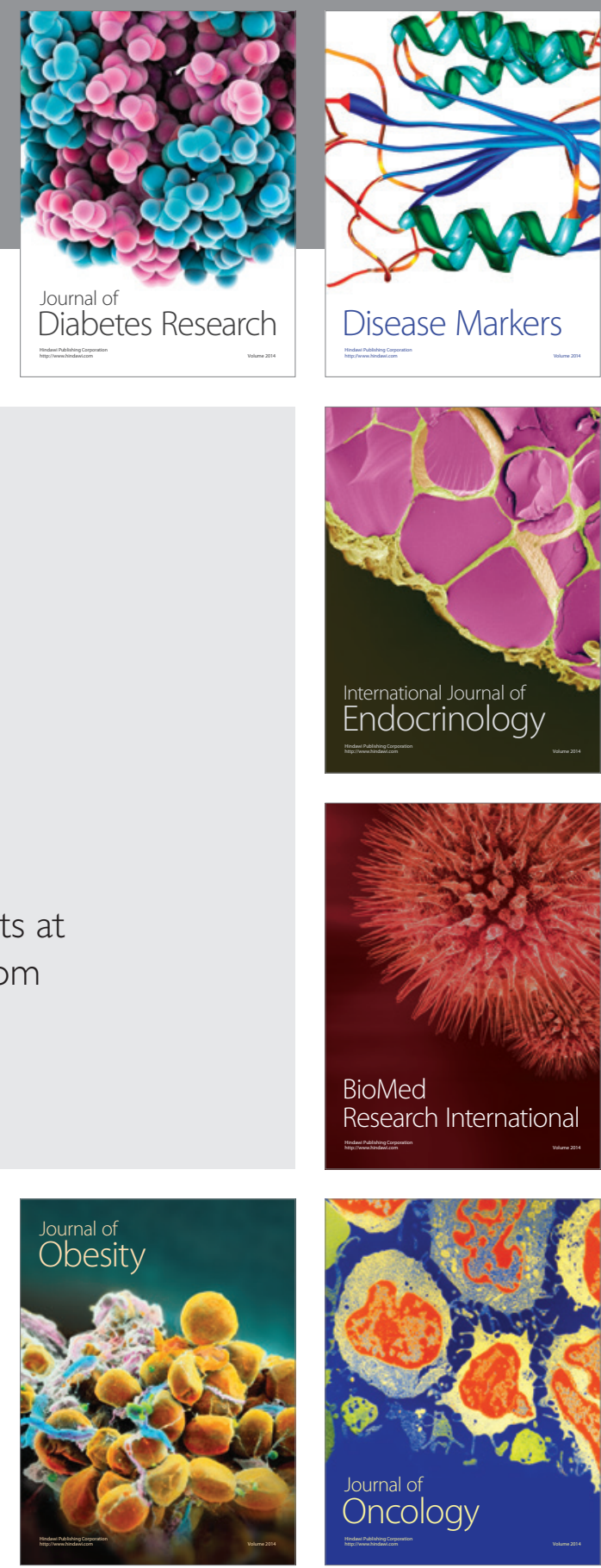

Disease Markers
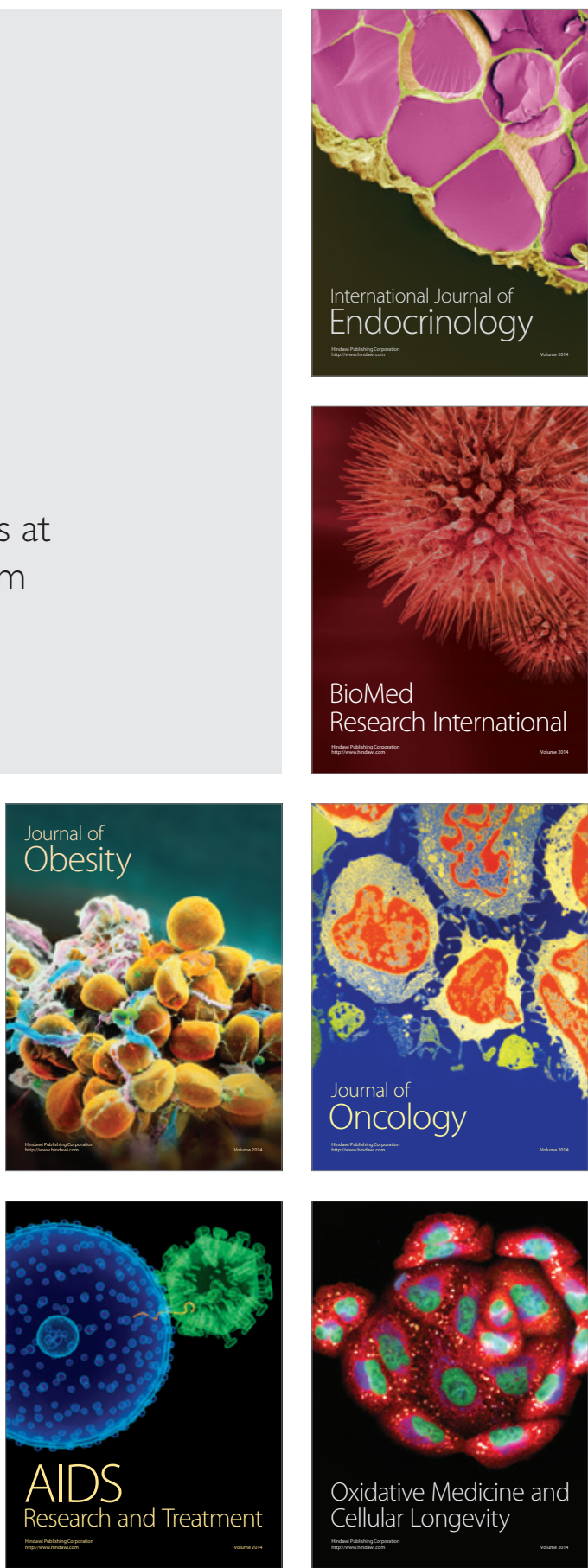